https://doi.org/10.22319/rmcp.v11i1.4902

Artículo

\title{
Caracterización técnica y ambiental de fincas de cría pertenecientes a muy pequeños, pequeños, medianos y grandes productores
}

Ricardo González-Quintero ab*

María Solange Sánchez-Pinzón ${ }^{\mathrm{c}}$

Diana María Bolívar-Vergara ${ }^{\mathrm{d}}$

Ngonidzashe Chirinda ${ }^{a}$

Jacobo Arango ${ }^{a}$

Heiber Alexander Pantévez ${ }^{\mathrm{e}}$

Guillermo Correa-Londoño ${ }^{\mathrm{d}}$

Rolando Barahona-Rosales ${ }^{\mathrm{d}}$

${ }^{a}$ Centro Internacional de Agricultura Tropical (CIAT), Km 17 recta Cali - Palmira, Valle del Cauca, Colombia, (0574) 4450000.

${ }^{\mathrm{b}}$ Universidad de Antioquia, Medellín, Colombia.

${ }^{c}$ Compañía Nacional de Chocolates, Rionegro, Antioquia, Colombia.

${ }^{d}$ Universidad Nacional de Colombia. Facultad de Ciencias Agrarias-Sede Medellín.

${ }^{\text {e }}$ Federación Colombiana de Ganaderos, Fedegán, Bogotá D.C, Colombia.

*Autor de correspondencia: ricardo.gonzalezq@udea.edu.co

\section{Resumen:}

En Colombia, la cría bovina representa $18.5 \%$ del inventario ganadero y es un eslabón importante en la cadena de producción de carne. La carencia de estudios de caracterización de sistemas de cría limita la planificación técnica y ambiental de esta actividad productiva. El objetivo de este estudio fue caracterizar los parámetros técnicos y ambientales de fincas de cría, pertenecientes a muy pequeños (MPG), pequeños (PG), medianos (MG) y grandes productores (GG). La información se obtuvo de los proyectos Ganadería Colombiana Sostenible y LivestockPlus, cuya muestra total fueron 2,618 fincas, clasificadas de acuerdo con su orientación productiva. De ésas, se 
estratificaron 251 fincas con orientación de cría en MPG (1 a 30 bovinos), PG (31 a 50), MG (51 a 250) y GG (más de 251). Se consideraron variables numéricas y categóricas distribuidas en cinco componentes: (1) información general, (2) composición y manejo del hato, (3) manejo de potreros, (4) información productiva y reproductiva e (5) información ambiental. Cada componente se analizó mediante un Análisis Factorial para Datos Mixtos (AFDM). De acuerdo con el AFDM de los primeros cuatro componentes, la distribución de las variables condujo a una separación espacial del centroide de cada categoría de ganaderos. Los MG y GG contaron con mejor infraestructura, maquinaria y equipos, y mejores prácticas y parámetros reproductivos y productivos. No existieron diferencias entre categorías en el desarrollo de prácticas ambientales. Las características identificadas pueden servir para el establecimiento de políticas públicas de desarrollo tecnológico y gestión ambiental.

Palabras clave: AFDM, Ganadería colombiana, Impactos ambientales, Políticas públicas, Producción ganadera.

Recibido: $17 / 05 / 2018$

Aceptado: 01/10/2018

\section{Introducción}

Colombia ocupa el cuarto lugar en Latinoamérica en inventario bovino ${ }^{(1)}$, en 2018 el hato colombiano alcanzó $26^{\prime} 413,227$ animales $^{(2)}$, con $45.7 \%$ de este inventario dedicado a la producción de carne, $39.3 \%$ al doble propósito y $15.0 \%$, a la lechería ${ }^{(3)}$. Esta actividad se desarrolla en 514,794 predios, de los cuales $412,829(80.2 \%)$ poseen menos de 50 cabezas $^{(2)}$ y sus productos principales son leche y carne. En el periodo 2014-2018, la producción nacional de leche promedió 6,816 millones de litros año ${ }^{-1}$ y la producción promedio de carne en canal para el mismo periodo fue de 926,858 toneladas año ${ }^{-1(4)}$.

La cadena de producción de carne colombiana está constituida por la cría y crecimiento, ceba y ciclo completo. La cría y crecimiento cuentan con $18.5 \%$ del inventario ganadero nacional y con $40.5 \%$ del inventario total de la cadena cárnica ${ }^{(3)}$. En su orden, los departamentos de Casanare, Meta, Antioquia, Santander, Córdoba y Tolima son los que cuentan con mayor número de animales en esta orientación ${ }^{(3)}$. La ganadería de carne colombiana puede considerarse como una actividad 
de producción extensiva, con bajos niveles de productividad ganadera y un inventario nacional estancado en años recientes ${ }^{(2)}$.

Debido a la importancia de los sistemas de cría para la producción de carne, es necesario identificar soluciones a sus limitantes productivas. Las caracterizaciones permiten conocer las fortalezas y debilidades de las fincas en sus componentes técnicos, productivos, reproductivos y ambientales ${ }^{(5)}$. Esto, posibilitaría el establecimiento de buenas prácticas ganaderas y desarrollar estrategias tecnológicas en pro del aumento de la productividad y disminución de los impactos ambientales negativos en las fincas.

El conocimiento de las características de estos sistemas de producción podría servir para el establecimiento de políticas de fomento y desarrollo en el sector ganadero colombiano. Además, puede orientar la implementación de la Acción Nacional Apropiada de Mitigación (NAMA por sus siglas en inglés) ganadera del país. La NAMA conlleva a alcanzar las metas de mitigación para el sector establecidas en la "Contribución Determinada a Nivel Nacional" (NDC por sus siglas en inglés), y presentada en 2015 ante la Comisión Marco de las Naciones Unidas sobre el Cambio Climático $^{(6)}$.

En Colombia, las caracterizaciones han sido desarrolladas en pocos departamentos y orientadas a sistemas de doble propósito y lechería $^{(7)}$. En contraste, solamente existe un estudio de caracterización para sistemas de producción de cría, por lo que no se cuenta con información suficiente para planificar esta actividad. En consecuencia, el presente artículo tiene como objetivo caracterizar los parámetros técnicos y ambientales de fincas de cría, pertenecientes a muy pequeños, pequeños, medianos y grandes productores, distribuidos en 13 departamentos de Colombia.

\section{Material y métodos}

\section{Población muestreada}

La información se obtuvo de los proyectos Ganadería Colombiana Sostenible (GCS) y Livestock Plus (L+). En el proyecto GCS, se realizaron 2,011 encuestas en fincas ganaderas, con diferente orientación productiva: cría, ceba, doble propósito, lechería especializada y ciclo completo. La selección de las zonas encuestadas se basó en la priorización de las regiones ganaderas más 
importantes en Colombia en cuanto a atributos ambientales, la existencia de ecosistemas de importancia global y la cercanía con áreas protegidas en la que coincidían áreas importantes para la producción ganadera. Las fincas ganaderas encuestadas pertenecen a los departamentos (entre paréntesis, el número de municipios): Atlántico (13), Bolívar (4), Boyacá (12), Caldas (2), Cesar (10), La Guajira (5), Meta (10), Quindío (9), Risaralda (2), Santander (4), Tolima (6) y Valle del Cauca (7). Los criterios que sirvieron para seleccionar las fincas incluidas en este muestreo fueron: estar ubicadas en regiones priorizadas por el proyecto GCS, poseer un área mayor a 2 ha y ser de propietarios colombianos. En cada finca se aplicó un cuestionario de diez componentes: (1) información general de la finca, (2) composición y manejo de la ganadería, (3) prácticas de manejo a potreros, (4) información productiva y reproductiva de la ganadería, (5) sanidad animal, (6) información ambiental, (7) información social, (8) información organizacional y relación con el medio externo, (9) ingresos de la ganadería e (10) información financiera.

Dentro del proyecto L+, se aplicaron encuestas a fincas ganaderas ubicadas en los municipios del Piedemonte (Cumaral y Restrepo) y la Altillanura (Puerto Gaitán y Puerto López), en Meta, y en el valle seco del Patía (El Bordo y Mercaderes), en Cauca. Se realizaron encuestas en 607 fincas ganaderas, así: Piedemonte (150), Altillanura (147) y valle seco del Patía (310). El cuestionario utilizado comprendió ocho componentes: (1) información general de la finca, (2) características administrativas de la finca, (3) características del uso del suelo en la finca, (4) asistencia técnica, (5) características productivas y reproductivas de la finca (6) asociación a cooperativas o gremios (7) información comercial y financiera y (8) eventos climáticos y prácticas ambientales.

A partir de la muestra total de 2,618 fincas ganaderas encuestadas, se identificaron 251 fincas de cría, de las cuales $165(65.7 \%)$ correspondieron a cría sin ordeño y $86(34.3 \%)$ a cría con doble utilización de la vaca. Las 251 fincas de cría se estratificaron de acuerdo a su inventario ganadero ${ }^{(8)}$ : muy pequeños (MPG: 1 a 30 bovinos), pequeños (PG: 31 a 50 bovinos), medianos (MG: 51 a 250 bovinos) y grandes (GG: más de 251 bovinos). Se consideraron variables numéricas y categóricas extraídas de los cuestionarios realizados en cada proyecto, las cuales fueron clasificadas en cinco componentes (Cuadro 1). 
Cuadro 1: Componentes y variables utilizadas para la caracterización de las fincas de cría

\begin{tabular}{|c|c|c|}
\hline Componente & Variables numéricas & Variables Categóricas \\
\hline $\begin{array}{l}\text { (1) Información } \\
\text { general }\end{array}$ & $\begin{array}{l}\text { Animales por finca; carga animal (Unidad Gran Ganado - UGG- } \\
\text { ha }^{-1} \text { ), área (ha): total de la finca, dedicada a la ganadería, cultivos } \\
\text { agroforestales, cultivos perennes, cultivos transitorios, } \\
\text { plantaciones forestales en monocultivo, pasturas mejoradas; } \\
\text { topografía (\%): plana, ondulada y quebrada; inventario de: } \\
\text { caballares, mulares, cerdos, caprinos, ovinos, gallinas y pollos. }\end{array}$ & $\begin{array}{l}\text { Instalaciones (establo, corral de manejo, brete, bodega); } \\
\text { maquinaria y equipos (tractor, motosierra, guadañadora, } \\
\text { motobomba, cerca eléctrica, electrobomba, báscula electrónica); } \\
\text { grandes especies (caballares, mulares y búfalos); medianas } \\
\text { especies (cerdos, caprinos y ovinos); pequeñas especies (gallinas } \\
\text { y pollos). }\end{array}$ \\
\hline $\begin{array}{l}\text { (2) Composición y } \\
\text { manejo del hato }\end{array}$ & $\begin{array}{l}\text { Inventario estratificado: vacas enproducción, vacas paridas, } \\
\text { vacas horras, terneras ( } 0-1 \text { año), terneros }(0-1 \text { año), hembras de } \\
\text { levante, machos de levante, novillas de vientre, novillos de ceba, } \\
\text { toros y toretes; tasa de suministro }\left(\mathrm{kg}^{-} \text {año }^{-1} \mathrm{UGG}^{-1}\right) \text { de: sales } \\
\text { mineralizadas, suplementos y concentrados. }\end{array}$ & $\begin{array}{l}\text { Utilización de registros (si, no); utilizaciór } \\
(\mathrm{si}, \mathrm{no}) \text {; sal blanca (si, no); suplementos ( } \\
(\mathrm{si}, \mathrm{no}) \text {. }\end{array}$ \\
\hline $\begin{array}{l}\text { (3) Manejo de } \\
\text { potreros }\end{array}$ & $\begin{array}{l}\text { Área de pasturas mejoradas, ha; Área fertilizada, ha; tasa de } \\
\text { aplicación }\left(\mathrm{kg} \mathrm{ha}^{-1} \mathrm{año}^{-1}\right) \text { de: fertilizantes y enmiendas. }\end{array}$ & $\begin{array}{l}\text { Pasturas mejoradas (si, no); rotación de potreros (si, no); división } \\
\text { de potreros (si, no; alambre de púa, cerca eléctrica, mixto); } \\
\text { cambio de área de potreros (si, no); método para desmalezar } \\
\text { (manual, mecánico, químico, mixto); fertilización (si, no); } \\
\text { enmiendas (cal agrícola, cal dolomita, otra); renovación de } \\
\text { potreros (si,no) }\end{array}$ \\
\hline $\begin{array}{l}\text { (4) Información } \\
\text { productiva } \\
\text { reproductiva }\end{array}$ & $\begin{array}{l}\text { Producción de leche, } \mathrm{L}_{\text {animal }}{ }^{-1} \text { día }^{-1} \text {; peso }(\mathrm{kg}) \text { de: nacimiento, } \\
\text { destete; peso final de engorde, }(\mathrm{kg}) \text {; edad al destete, meses; edad } \\
\text { final de engorde, meses; ganancia diaria de peso }{ }^{\mathrm{a}} \text { ( } \mathrm{kg} \mathrm{día}^{-1} \\
\text { predestete }^{\mathrm{b}} \text {, ceba }^{\mathrm{c}} \text {; tasa de mortalidad, \%. }\end{array}$ & $\begin{array}{l}\text { Tipo de ordeño (manual, mecánico), pesaje de animales (cinta } \\
\text { métrica, báscula); pesaje al nacimiento (si, no); pesaje al destete } \\
\text { (si, no); sistema de reproducción (monta natural libre, monta } \\
\text { natural controlada, inseminación artificial, transferencia de } \\
\text { embriones); chequeo reproductivo a vacas y toros (si, no); pesaje } \\
\text { de novillas de vientre para el primer servicio (si, no); inseminador } \\
\text { (si, no); equipo de inseminación artificial (si, no); separación del } \\
\text { lote horro (si, no); potrero de paridero (si, no); determinación del } \\
\text { intervalo entre partos (si, no). }\end{array}$ \\
\hline $\begin{array}{l}\text { (5) Información } \\
\text { ambiental }\end{array}$ & --- & $\begin{array}{l}\text { Bosque (si, no); fuente de suministro de agua (superficial, } \\
\text { subterránea, acueducto); nacimientos de agua (si, no); } \\
\text { disponibilidad de agua en verano para uso pecuario (si, no); } \\
\text { sistema de riego (si, no); sistema de tratamiento de aguas } \\
\text { residuales (si, no); manejo de residuos sólidos (incinera, entierra, } \\
\text { entrega a terceros). }\end{array}$ \\
\hline
\end{tabular}

${ }^{a}$ Ganancia diaria de peso $\left(\mathrm{kg} \mathrm{día}^{-1}\right)$ : fue estimado basado en el peso al inicio y al final de las etapas de destete y ceba, y en el tiempo de duración de cada una de estas dos etapas; ${ }^{\mathrm{b}}$ Etapa correspondiente desde el nacimiento hasta el destete; ${ }^{\mathrm{c}}$ Etapa correspondiente desde el destete hasta el sacrificio

\section{Análisis estadísticos}

La evaluación integral de cada uno de los cinco componentes descritos se realizó mediante la técnica multivariante Análisis Factorial para Datos Mixtos (AFDM), usando la función FAMD del paquete FactoMineR para $\mathrm{R}^{(9)}$. AFDM es un método factorial utilizado para analizar un conjunto de datos donde un grupo de individuos se describen mediante variables cuantitativas y cualitativas. El término "mixto" se refiere a la presencia simultánea, como elementos activos, de variables cualitativas y cuantitativas en unidades de muestreo. El AFDM permite la exploración simultánea de dichas variables mediante la combinación de análisis de componentes principales (ACP) y análisis de correspondencias múltiples $(\mathrm{ACM})^{(10)}$. Las variables cuantitativas fueron centradas y normadas a valores $\mathrm{Z}$, mientras que las cualitativas fueron desagregadas en una matriz disyuntiva 
normalizada. Partiendo de muestras mixtas, este método permite estudiar gráficamente las similitudes/disimilitudes entre unidades productivas (distancias) y las correlaciones entre las variables continuas ${ }^{(10)}$. Previamente a la aplicación del AFDM, se realizó una imputación de los datos perdidos, mediante el algoritmo implementado en la función imputeFAMD, que forma parte del paquete missMDA ${ }^{(11)}$. Las variables categoría de productor y número de animales fueron incluidas en el AFDM como suplementarias para evitar su participación en la construcción del modelo.

\section{Resultados y discusión}

El Cuadro 2 presenta las características generales de las fincas. El 74.5\% de las fincas correspondió a MPG y PG, y $25.4 \%$ a MG y GG. Este comportamiento muestra similitudes con la distribución porcentual de las explotaciones ganaderas en Colombia establecida por Fedegán ${ }^{(8)}$ y el Instituto Colombiano Agropecuario ${ }^{(2)}$, donde el $81 \%$ de las fincas con presencia de bovinos cuentan con menos de 50 animales y $18 \%$ albergan entre 51 y 500 cabezas de ganado. Por su parte, Ríos-Núñez y Benítez-Jiménez ${ }^{(12)}$ reportaron que en sistemas de cría en la Amazonía ecuatoriana las fincas con rebaños entre 1 y 30 cabezas de ganado fueron $64.5 \%$ del total. Esto sugiere que, las futuras políticas públicas agropecuarias encaminadas al mejoramiento productivo y reproductivo podrían estar focalizadas en este tipo de ganaderos.

Cuadro 2: Características biofísicas y de usos del suelo de las fincas de cría por grupo de ganaderos (promedio \pm desviación estándar)

\begin{tabular}{|c|c|c|c|c|}
\hline Variable & MPG & PG & MG & GG \\
\hline Número total de productores & $162(64.5 \%)$ & $25(10.0 \%)$ & $59(23.5 \%)$ & $5(2.0 \%)$ \\
\hline Animales por finca, número & $13.4 \pm 7.7$ & $39.4 \pm 6.9$ & $108.8 \pm 56.6$ & $329.2 \pm 57.1$ \\
\hline Área total de la finca, ha & $16.3 \pm 26.3$ & $40.6 \pm 39.6$ & $93.8 \pm 76.9$ & $135.3 \pm 43.3$ \\
\hline Área dedicada a la ganadería & $16.2 \pm 26.4$ & $40.4 \pm 39.6$ & $93.4 \pm 77.0$ & $134.9 \pm 43.3$ \\
\hline $\begin{array}{l}\text { Número de Unidad Gran Ganado (UGG) por } \\
\text { finca }\end{array}$ & $10.0 \pm 5.9$ & $30.8 \pm 7.3$ & $80.1 \pm 43.2$ & $253.5 \pm 32.6$ \\
\hline Carga animal, UGG ha' ${ }^{-1}$ & $1.2 \pm 0.9$ & $1.5 \pm 1.1$ & $1.3 \pm 0.9$ & $2.1 \pm 0.7$ \\
\hline $\begin{array}{l}\text { Fincas que cuentan con cultivos } \\
\text { agroforestales, } \%\end{array}$ & 8.5 & 0 & 1.9 & 0 \\
\hline $\begin{array}{l}\text { Área de la finca con cultivos agroforestales, } \\
\% \text { del área total* }\end{array}$ & $13.3 \pm 11.8$ & --- & 15.0 & --- \\
\hline Fincas que cuentan con cultivos perennes, $\%$ & 10.2 & 20.0 & 9.3 & 20.0 \\
\hline $\begin{array}{l}\text { Área de la finca con cultivos perennes, } \% \text { del } \\
\text { área total* }\end{array}$ & $11.1 \pm 15.0$ & $2.3 \pm 0.9$ & $2.9 \pm 4.9$ & 0.6 \\
\hline $\begin{array}{l}\text { Fincas que cuentan con cultivos transitorios, } \\
\%\end{array}$ & 7.0 & 10.0 & 5.6 & 20.0 \\
\hline
\end{tabular}


Área de la finca con cultivos transitorios, \% del área total*

Fincas que cuentan con pasturas mejoradas, $\%$

Área de la finca con pasturas mejoradas, \% del área total*

Área plana de la finca, \% del área total

MPG: muy pequeños ganaderos, PG: pequeños ganaderos, MG: medianos ganaderos, GG: grandes ganaderos *Promedio calculado con las fincas que contaban con este tipo de cultivo.

\begin{tabular}{cccc}
$12.9 \pm 14.2$ & $16.8 \pm 0.2$ & $10.2 \pm 9.7$ & 3.00 \\
47.5 & 30.0 & 33.3 & 40.0 \\
$25.7 \pm 34.0$ & $21.4 \pm 35.5$ & $20.0 \pm 30.7$ & $24.8 \pm 42.9$ \\
$48.2 \pm 38.3$ & $50.5 \pm 37.6$ & $54.5 \pm 39.5$ & $62.0 \pm 52.2$ \\
\hline \multicolumn{4}{l}{ ganaderos, MG: medianos ganaderos, GG: grandes ganaderos } \\
fincas que contaban con este tipo de cultivo.
\end{tabular}

Las Figuras 1, 2, 3, 4 y 5 representan los AFDM para cada uno de los cinco componentes evaluados e incluyen: (a) la relación espacial entre los centroides de las variables cualitativas, con categoría de productor como variable suplementaria y (b) la proyección de las variables continuas sobre el plano de las primeras dos dimensiones factoriales, con número de animales como variable suplementaria. Las dos primeras dimensiones capturaron 39.5, 24.8, 29.7, 47.2 y $37.9 \%$ de la variabilidad presente en los componentes Información General de la Finca (Figura 1), Composición y Manejo del Hato (Figura 2), Manejo de Potreros (Figura 3), Información Productiva y Reproductiva (Figura 4) e Información Ambiental (Figura 5), respectivamente. Las variables suplementarias no participaron en la construcción del modelo. Hubo una clara separación del centroide de los diferentes grupos (MPG, PG, MG y GG) en los primeros cuatro componentes evaluados. Para el componente ambiental no existió separación del centroide, lo que sugiere que, no existen marcadas diferencias en el desarrollo e implementación de prácticas ambientales asociadas con el tamaño del productor.

\section{Información general de la finca}

La configuración de las variables categóricas que caracterizan la información general da lugar a un alineamiento ordenado de las categorías de productor sobre la primera dimensión de la representación del AFDM (Figura 1 a). Existió una estrecha asociación entre las variables relacionadas con la existencia de maquinaria y equipos (báscula electrónica, tractor, motosierra, motobomba, electrobomba, corral de manejo, establo, brete y bodega) y las categorías GG y MG. Por el contrario, las variables relacionadas con el no uso de estas tecnologías se ubicaron hacia el lado izquierdo de la dimensión 1, donde también se ubicaron la existencia de cultivos agroforestales y plantaciones forestales en monocultivo, asociadas con las categorías MPG y PG. En la dimensión 2, la existencia de pequeñas, medianas y grandes especies, el uso de guadañadora y cerca eléctrica se aglomeraron en la parte inferior, mientras que la no presencia y/o uso de las anteriores variables se localizaron en la parte superior, sin que se sugiera alguna relación entre tales factores y la categoría de productor. 
Figura 1: Proyección espacial de las categorías de variables categóricas (a) y numéricas (b)
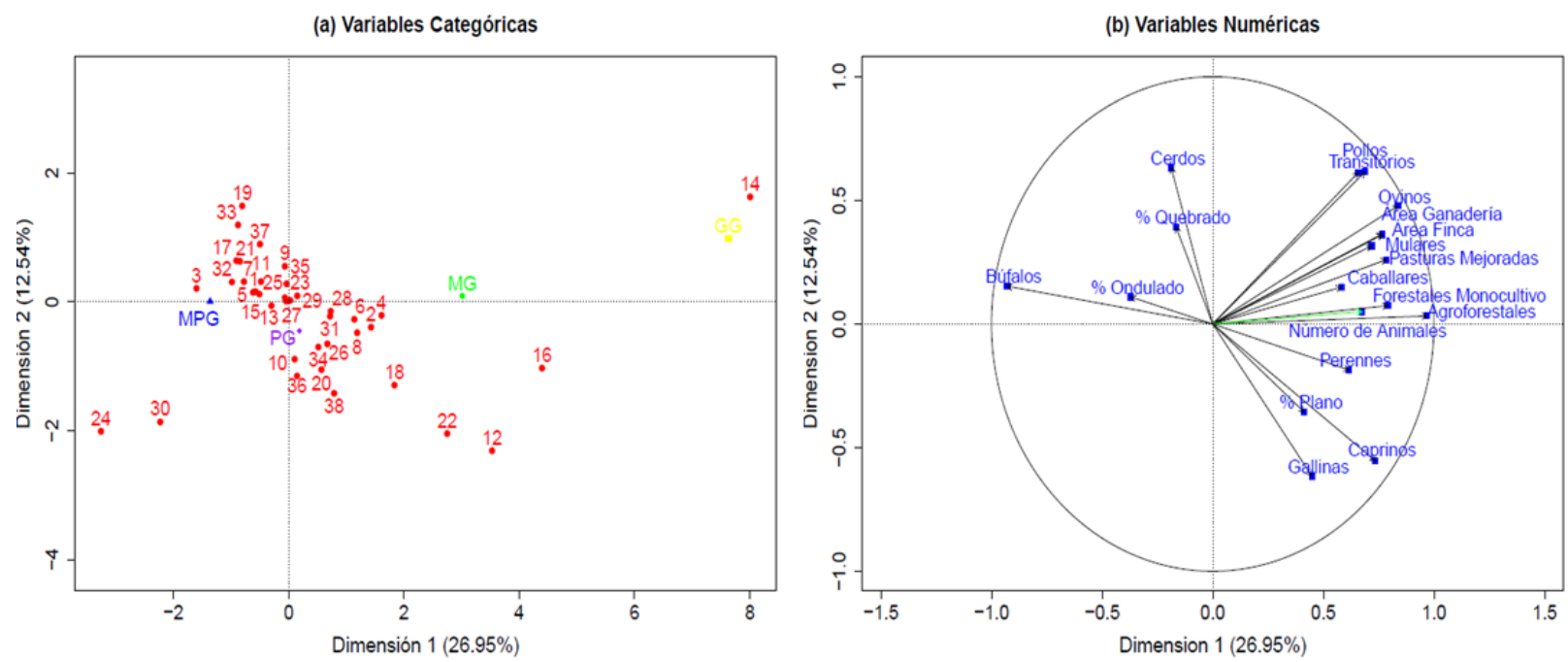

Proyección espacial (a) de las categorías de variables categóricas (GG: grandes ganaderos, MG: medianos ganaderos, PG: pequeños ganaderos, MPG: muy pequeños ganaderos, 1: no establo, 2: si establo, 3: no corral de manejo, 4: si corral de manejo, 5: no brete, 6: si brete, 7: no bodega, 8: si bodega, 9: no cerca eléctrica, 10: si cerca eléctrica, 11: no electrobomba, 12: si electrobomba, 13: no báscula electrónica, 14: si báscula electrónica, 15: no tractor, 16: si tractor, 17: no motosierra, 18: si motosierra, 19: no guadañadora, 20: si guadañadora, 21: no motobomba, 22: si motobomba, 23: no cultivos agroforestales, 24: si cultivos agroforestales, 25: no cultivos perennes, 26: si cultivos perennes, 27: no cultivos transitorios, 28: si cultivos transitorios, 29: no plantaciones forestales en monocultivo, 30: si plantaciones forestales en monocultivo, 31: no pasturas mejoradas, 32: si pasturas mejoradas, 33: no grandes especies, 34: si grandes especies, 35: no medianas especies, 36: si medianas especies, 37: no pequeñas especies, 38: si pequeñas especies) y (b) numéricas (Área Finca: área total de la finca, \% Plano: área de la finca plana, \% Ondulado: área de la finca ondulada, \% Quebrado: área de la finca quebrada, Agroforestales: área de cultivos agroforestales, Perennes: área de cultivos perennes, Transitorios: área de cultivos transitorios, Forestales Monocultivo: área de plantaciones forestales en monocultivo, Pasturas Mejoradas: área de pasturas mejoradas , Área Ganadería: área dedicada a la ganadería, Búfalos: número de búfalos, Caballares: número de caballares, Mulares: número de mulares, Cerdos: número de cerdos, Caprinos: número de caprinos, Ovinos: número de ovinos, Gallinas: número de gallinas, Pollos: número de pollos, Número de Animales: número de bovinos) en la primera y segunda dimensión del componente Información General de la Finca. MPG: muy pequeños ganaderos, PG: pequeños ganaderos, MG: medianos ganaderos, GG: grandes ganaderos.

En relación con las variables numéricas, el área total de la finca, área dedicada a la ganadería, área de pasturas mejoradas, área de cultivos agroforestales, área de plantaciones forestales en monocultivo y área de cultivos transitorios, estuvieron relacionadas positivamente con la primera dimensión, la cual representa el tamaño de las fincas (Figura 1 (b)). Adicionalmente, estas variables mostraron alta relación con el número de animales. El número de búfalos y el porcentaje del área de la finca ondulada se relacionaron negativamente con la dimensión 1, lo que significa que tales condiciones son más propias de las fincas pequeñas. Con respecto a la segunda dimensión, las variables número de cerdos y porcentaje del área de la finca quebrada se relacionaron positivamente con esta dimensión, mientras que el número de gallinas, de caprinos y el porcentaje de áreas planas, negativamente. 
Los MG y GG al estar asociados con la existencia de infraestructura (maquinaria, equipos e instalaciones), reflejan una mayor capacidad económica. Similarmente, Holmann et al ${ }^{(7)}$ reportaron que los ganaderos con mayor número de bovinos obtienen mayores ingresos y ganancias que los ganaderos pequeños, lo que les permite obtener instalaciones, equipos y maquinaria en mayor cantidad y mejores condiciones, dado que estos son un rubro costoso en la producción ganadera. Adicionalmente, Chalate-Molina et $a l^{(13)}$ reportaron observaciones similares en México, al determinar que, en las fincas más grandes la disponibilidad de maquinaria y equipo fue mayor y más adecuada para el desarrollo de las actividades ganaderas.

Las fincas más grandes se relacionaron de forma negativa con el porcentaje del área de la finca ondulada y positivamente con la presencia de mulares y caballares (grandes especies). Es importante destacar que, la presencia y explotación de otras especies animales es una medida que podría favorecer la (i) disponibilidad, (ii) estabilidad, (iii) acceso y (iv) consumo de alimentos, garantizando así las cuatro dimensiones de la seguridad alimentaria, lo cual podría beneficiar la sostenibilidad de los ganaderos ${ }^{(14)}$.

Se considera que terrenos con pendiente pronunciada (mayor que $30 \%$ ) no son aptos para pastoreo $^{(12)}$. Los porcentajes del área de la finca con topografía quebrada (pendiente mayor que $60 \%)$ de los MPG $(25.5 \%)$ y PG $(22.0 \%)$ fueron mayores que los presentados por los MG $(14.2 \%)$ y GG $(10.5 \%)$. La ganadería desarrollada en terrenos con pendientes altas podría ocasionar degradación de tierras debido al aumento de la erosión asociada con el pisoteo del ganado $^{(15)}$. Esto conlleva a la disminución de la capacidad de infiltración y el aumento de la escorrentía superficial en épocas de $\mathrm{AUvia}^{(16)}$, traduciéndose en menor producción de biomasa y productividad ganadera. Cabe destacar que a medida que las pasturas se degradan, las emisiones anuales netas de GEI en las fincas tienden a aumentar ${ }^{(17)}$. Por tanto, es importante estimar este tipo de emisiones en las fincas, para identificar el aporte a las emisiones globales de GEI del sistema y proponer acciones de mitigación adecuadas.

El número de fincas que realizaron actividades agrícolas o contaron con algún tipo de cultivo es bajo en las categorías evaluadas (Cuadro 2). Esto contrasta con lo encontrado al caracterizar fincas de pequeños ganaderos en Veracruz, México ${ }^{(18)}$, donde el $85 \%$ de los pequeños ganaderos combinaron la actividad pecuaria con agricultura. El área de la finca dedicada a cultivos es igualmente bajaiError! No se encuentra el origen de la referencia.. Así, dado que los sistemas de cría en Colombia corresponden a sistemas extensivos en un alto porcentaje ${ }^{(19)}$, los actuales resultados son similares a los reportados para sistemas ganaderos extensivos y semi-extensivos en México $^{(20)}$, donde el área de la finca dedicada a cultivos fue menor que $20 \%$. El desarrollo de actividades agrícolas y pecuarias conjuntamente es una estrategia que permite garantizar las dimensiones de la seguridad alimentaria. Además, podría contribuir en la adaptación y mitigación 
al cambio climático, por ejemplo, mediante la incorporación de cultivos de ciclo corto o transitorios a los sistemas de pastoreo $^{(21)}$.

\section{Componente técnico}

\section{Composición y manejo del hato}

El Cuadro 3 presenta la composición del hato, las tasas de suministro de alimentación complementaria y los parámetros productivos y reproductivos para cada categoría de ganaderos.

Cuadro 3: Composición del hato, parámetros productivos, reproductivos, y tasas de suministro de alimentación complementaria por categoría de ganadero de fincas dedicadas a la cría (promedio \pm desviación estándar)

\begin{tabular}{|c|c|c|c|c|}
\hline Variable & MPG & PG & MG & GG \\
\hline \multicolumn{5}{|l|}{ Composición del hato: } \\
\hline Vacas en producción, UGG & $1.1 \pm 2.3$ & $2.0 \pm 4.0$ & $3.7 \pm 9.8$ & $19.0 \pm 42.5$ \\
\hline Vacas paridas, UGG & $2.5 \pm 3.3$ & $8.9 \pm 6.4$ & $25.5 \pm 26.6$ & $58.4 \pm 42.2$ \\
\hline Vacas horras, UGG & $2.1 \pm 2.7$ & $9.4 \pm 10.1$ & $18.1 \pm 19.8$ & $83.4 \pm 33.6$ \\
\hline Terneras de 0 a 1 año, UGG & $0.5 \pm 0.6$ & $1.3 \pm 1.1$ & $4.5 \pm 3.9$ & $11.6 \pm 3.2$ \\
\hline Terneros de 0 a 1 año, UGG & $0.4 \pm 0.4$ & $1.1 \pm 0.9$ & $3.9 \pm 3.3$ & $8.9 \pm 4.7$ \\
\hline Hembras de 1 a 2 años, UGG & $1.0 \pm 1.9$ & $2.3 \pm 3.0$ & $6.2 \pm 7.1$ & $20.5 \pm 22.4$ \\
\hline Machos de 1 a 2 años, UGG & $0.9 \pm 1.9$ & $1.0 \pm 1.8$ & $3.5 \pm 6.9$ & $9.4 \pm 18.3$ \\
\hline Novillas de vientre de 2 a 3 años, UGG & $1.2 \pm 2.5$ & $4.4 \pm 5.8$ & $7.7 \pm 11.6$ & $13.0 \pm 15.8$ \\
\hline Novillos de ceba de 2 a 3 años, UGG & $0.3 \pm 1.3$ & $0.4 \pm 1.2$ & $4.9 \pm 12.7$ & $23.8 \pm 53.3$ \\
\hline Toros, UGG & $0.5 \pm 0.7$ & $1.0 \pm 1.1$ & $3.7 \pm 5.7$ & $5.5 \pm 3.5$ \\
\hline \multicolumn{5}{|l|}{ Alimentación complementaria: } \\
\hline Tasa de concentrados, $\mathrm{kg}$ año ${ }^{-1} \mathrm{UGG}^{-1} *$ & $53.6 \pm 25.3$ & $55.8 \pm 30.1$ & $60.6 \pm 45.5$ & $85.4 \pm 75.9$ \\
\hline Tasa de suplementos, $\mathrm{kg}$ año ${ }^{-1} \mathrm{UGG}^{-1} *$ & $16.5 \pm 22.5$ & $15.9 \pm 15.5$ & $33.8 \pm 22.2$ & $34.3 \pm 30.6$ \\
\hline $\begin{array}{l}\text { Tasa de sales mineralizadas, } \mathrm{kg} \mathrm{año}^{-1} \\
\mathrm{UGG}^{-1 *}\end{array}$ & $32.3 \pm 5.7$ & $30.7 \pm 3.4$ & $32.4 \pm 3.2$ & $31.6 \pm 1.4$ \\
\hline \multicolumn{5}{|l|}{ Parámetros productivos y reproductivos: } \\
\hline Peso al nacimiento, $\mathrm{kg}$ & $31.5 \pm 4.4$ & $32.3 \pm 4.4$ & $34.1 \pm 4.0$ & $34.3 \pm 4.0$ \\
\hline Peso al destete, $\mathrm{kg}$ & $149.4 \pm 34.8$ & $175.0 \pm 46.2$ & $179.2 \pm 42.3$ & $176.7 \pm 5.8$ \\
\hline Edad al destete, meses & $7.3 \pm 1.1$ & $7.8 \pm 1.4$ & $8.0 \pm 0.9$ & $8.0 \pm 1.7$ \\
\hline $\begin{array}{l}\text { Ganancia diaria de peso predestete, } \mathrm{kg} \\
\text { día }^{-1}\end{array}$ & $0.60 \pm 0.22$ & $0.59 \pm 0.17$ & $0.61 \pm 0.18$ & $0.63 \pm 0.15$ \\
\hline Porcentaje de mortalidad, $\%$ & $14.6 \pm 10.9$ & $6.1 \pm 3.4$ & $3.8 \pm 3.0$ & $3.0 \pm 2.9$ \\
\hline Producción de leche, $\mathrm{L}_{\text {animal }}{ }^{-1}$ día $^{-1}$ & $3.4 \pm 1.4$ & $3.5 \pm 1.3$ & $2.8 \pm 1.7$ & $2.9 \pm 1.5$ \\
\hline
\end{tabular}

MPG: muy pequeños ganaderos, PG: pequeños ganaderos, MG: medianos ganaderos, GG: grandes ganaderos *Promedio calculado con las fincas que realizaron esta práctica. 
Con respecto a las variables categóricas (Figura 2 (a)), aquellas relacionadas con el suministro de suplementos, concentrados y sal mineralizada se concentraron hacia la izquierda de la dimensión 1 , y las variables afines con el no suministro de dichos insumos y el uso de sal blanca se localizaron hacia la derecha. En la dimensión 2, la variable uso de registros de la ganadería se ubicó en la parte superior del gráfico, mientras que la carencia de registros se localizó en la parte inferior. Por tanto, los PG, MG y GG llevaron registros de la ganadería y suministraron en mayor proporción alimentación complementaria, mientras que los MPG se caracterizaron principalmente por el suministro de sal blanca, el no uso de registros de la ganadería y el no suministro de concentrados ni suplementos.

En relación con las variables numéricas, la tasa de suministro de sal mineralizada ( $\mathrm{kg}_{\text {año }}{ }^{-1}$ Unidad Gran Ganado $\left(\mathrm{UGG}^{-1}\right)$ se relacionó positivamente con la dimensión 1, mientras que la tasa de suministro de concentrados y suplementos $\left(\mathrm{kg} \mathrm{año}^{-1} \mathrm{UGG}^{-1}\right)$ se relacionaron negativamente (Figura 2 (b)). Así, los MG y GG presentaron mayores tasas de suministro de concentrados y suplementos (Cuadro 3). Por su parte, las variables vacas por toro, porcentaje de terneros, porcentaje de terneras, porcentaje de vacas paridas y porcentaje de vacas en ordeño se relacionaron positivamente con la dimensión 2. Adicionalmente, estas variables tuvieron relación con la variable número de animales. Por otra parte, el porcentaje de machos de levante, porcentaje de toros y porcentaje de novillos de ceba se relacionaron negativamente con esta dimensión.

Figura 2: Proyección espacial de las categorías de variables categóricas (a) y numéricas (b)
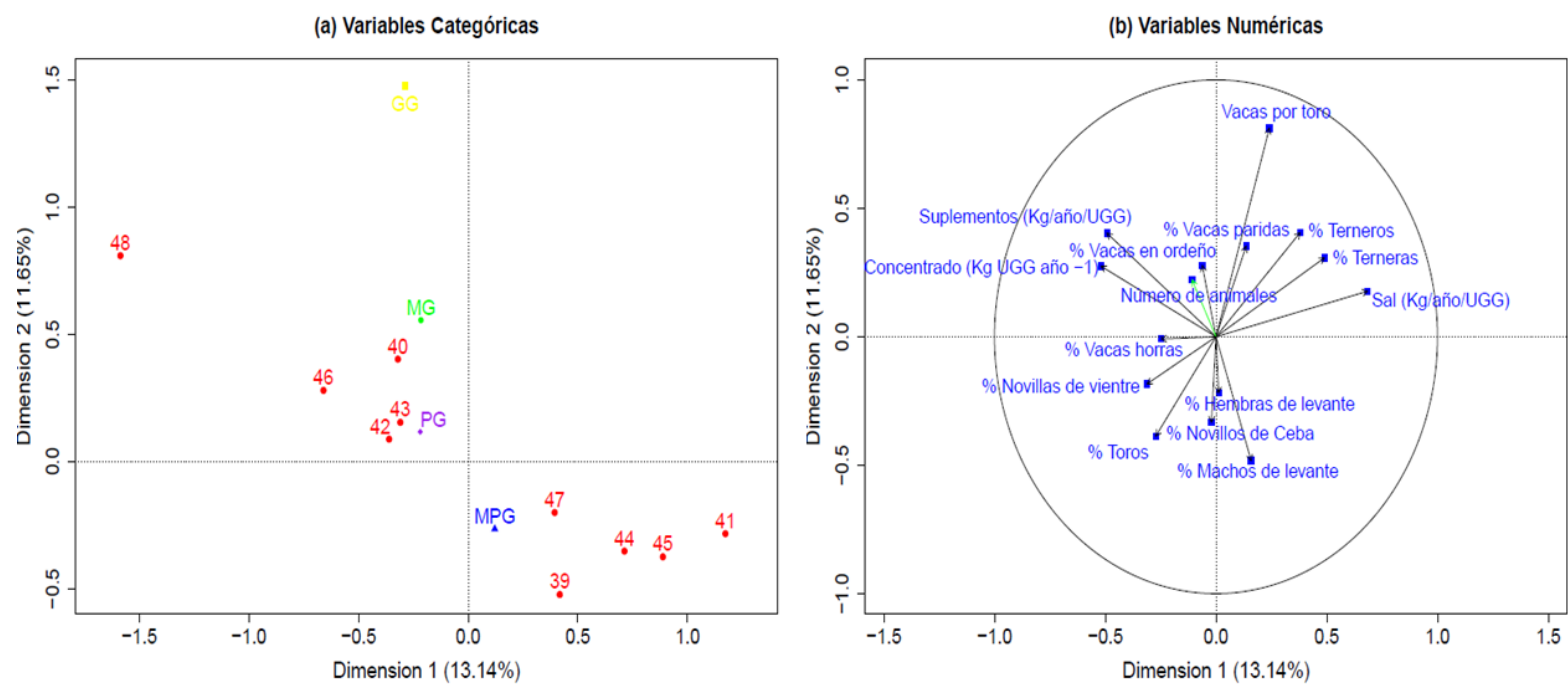

Proyección espacial de las categorías de variables categóricas (GG: grandes ganaderos, MG: medianos ganaderos, PG: pequeños ganaderos, MPG: muy pequeños ganaderos, 39: no registros de la ganadería, 40: si registros de la ganadería, 41: no uso de sal mineralizada, 42: si uso de sal mineralizada, 43: no uso de sal blanca, 44: si uso de sal blanca, 45: no uso de suplementos, 46: si uso de suplementos, 47: no uso de concentrado, 48: si uso de concentrado) y (b) numéricas (Vacas por toro: número de vacas por toro, \% Vacas en ordeño: \% de vacas en ordeño, \% Vacas paridas: $\%$ de vacas paridas, $\%$ Vacas horras: $\%$ de vacas horras, $\%$ Terneras: $\%$ de terneras de 0 a 1 año, $\%$ 
Terneros: $\%$ de terneros de 0 a 1 año, $\%$ Hembras de levante: $\%$ de hembras de levante, $\%$ Machos de levante: $\%$ de machos de levante, $\%$ Novillas de vientre: $\%$ de novillas de vientres, $\%$ Novillos de Ceba: $\%$ de novillos de ceba, $\%$ Toros: \% de toros, Concentrado (Kg UGG-1 año -1): tasa de suministro de concentrados, Suplementos (Kg UGG-1 año-1 ): tasa de suministro de suplementos, Sal (Kg UGG-1 año-1): tasa de suministro de sales, Número de animales: número de bovinos) en la primera y segunda dimensión del componente Composición y Manejo del Hato. MPG: muy pequeños ganaderos, PG: pequeños ganaderos, MG: medianos ganaderos, GG: grandes ganaderos.

La mayoría de los pastos cultivados en el trópico son deficientes en minerales y las fincas de cría corresponden en su mayoría a sistemas de pastoreo extensivos que cuentan con altos porcentajes de pasturas naturales. Por tanto, la suplementación con minerales es necesaria con el fin de minimizar los efectos negativos del déficit de macro y micronutrientes ${ }^{(22)}$. El uso de sal mineralizada estuvo asociado a los MG y GG, mientras que el uso de sal blanca se asoció con los MPG. De acuerdo con esto, los MG y GG suministran una gama mayor de minerales, lo cual podría garantizar un mejor comportamiento reproductivo y productivo en comparación con los MPG, quienes no realizan este tipo de suplementación posiblemente por elevados costos de adquisición o aspectos culturales.

El uso de alimentos concentrados estuvo más asociado a los GG. Las fincas más grandes tienden a tener mayores porcentajes de vacas en ordeño y presentaron tasas de suplementación más altas (Cuadro 3). En diferentes estudios de caracterización de sistemas extensivos, los GG se han mostrado como los que perciben mayores ingresos económicos. Esto, les posibilita la adquisición de suplementos alimenticios, uno de los gastos de mayor cuantía en los hatos ${ }^{(12)}$ y que se podría traducir en mayor productividad. Por su parte, en sistemas de cría con ordeño en Cundinamarca, Colombia, los pequeños y medianos productores no suministraron suplementos ni concentrados y la alimentación de los animales consistió principalmente en el pastoreo de praderas naturales ${ }^{(23)}$. Los MPG, PG y MG al basar la alimentación de sus animales en pasturas naturales y/o degradadas y en menor medida en concentrados y pastos mejorados, podrían tener menores rendimientos productivos.

El bajo uso de registros y control de las actividades productivas y reproductivas asociado con los MPG, coincide con lo reportado para pequeños productores de cría en Cundinamarca, Colombia ${ }^{(23)}$. El fomento de la tenencia de registros y controles técnicos podría ayudar a realizar un adecuado seguimiento de los parámetros productivos y reproductivos de las fincas. Esta es una herramienta importante para la toma de decisiones por parte de los ganaderos con el fin de incrementar la productividad. 


\section{Manejo de potreros}

Con respecto a las variables categóricas (Figura 3 (a)), hacia el lado derecho de la dimensión 1 se observa una clara tendencia de aglomeración de las variables relacionadas con la implementación de fertilización química, prácticas de renovación, rotación y cambio de área de potreros, aplicación de enmiendas y uso de cercado eléctrico. Por el contrario, las variables relacionadas con la no implementación de dichas prácticas y/o actividades tienden a orientarse hacia el lado izquierdo de esta dimensión. Con referencia a la dimensión 2, las variables división de potreros mixta (alambre y cerca eléctrica) y el control de malezas mediante los métodos químico y mixto se aglomeraron en la parte superior, mientras que las variables de no adopción de estas prácticas se localizaron en la parte inferior. Los MG, GG y PG tienden a desarrollar en mayor medida prácticas de mejoramiento y conservación de potreros.

La rotación y división de potreros mediante el método mixto se relacionaron con los MG y GG (Figura 3 (a)). En estas fincas se desarrolló pastoreo alterno y rotacional. Un adecuado sistema de rotación contribuye a aumentar la cantidad y calidad de biomasa, e incrementar la productividad del sistema ganadero ${ }^{(24,25)}$. Adicionalmente, la utilización de cercas eléctricas permite cambiar el área de los potreros, lo cual favorece el manejo adecuado de pastizales y el incremento de la productividad. Por tanto, en las fincas con mayor número de animales, la rotación de potreros y la utilización de cercas eléctricas podrían beneficiar el comportamiento productivo.

Figura 3: Proyección espacial de las categorías de variables categóricas (a) y numéricas (b)
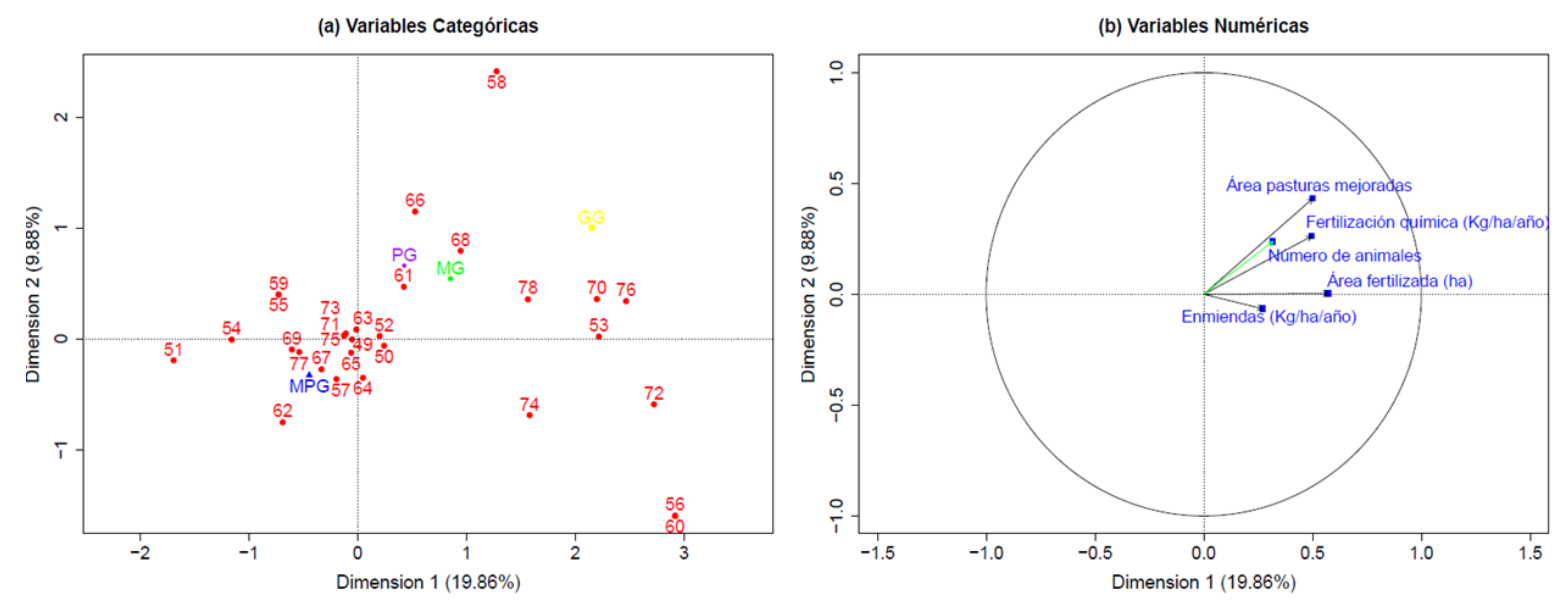

Proyección espacial (a) de las categorías de variables categóricas (GG: grandes ganaderos, MG: medianos ganaderos, PG: pequeños ganaderos, MPG: muy pequeños ganaderos, 49: no pasturas mejoradas, 50: si pasturas mejoradas, 51: no rotación de potreros, 52: si rotación de potreros, 53: no división de potreros con alambre de púas, 54: si división de potreros con alambre de púas, 55: no división de potreros con cerca eléctrica, 56: si división de potreros con cerca eléctrica, 57: no división de potreros mixta - incluye cerca eléctrica y alambre púa -, 58: si división de potreros mixta - incluye cerca eléctrica y alambre púa -, 59: no cambia el área de potreros, 60: si cambia el área de potreros, 61: no 
realiza control manual de malezas, 62: si realiza control manual de malezas, 63: no realiza control mecánico de malezas, 64: si realiza control mecánico de malezas, 65: no realiza control químico de malezas, 66: si realiza control químico de malezas, 67: no realiza control mixto de malezas, 68: si realiza control mixto de malezas, 69: no realiza fertilización química, 70: si realiza fertilización química, 71: no usa cal agrícola, 72: si usa cal agrícola, 73: no usa cal dolomita, 74: si usa cal dolomita, 75: no usa otro tipo de enmienda, 76: si usa otro tipo de enmienda, 77: no hace renovación de potreros, 78: si hace renovación de potreros) y (b) numéricas (Área pasturas mejoradas: área de pasturas mejoradas, Fertilización química (Kg ha-1 año-1): tasa de fertilización química, Área fertilizada (ha): área de la finca fertilizada, Enmiendas (Kg ha-1 año-1): tasa de aplicación de enmiendas, Número de animales: número de bovinos) en la primera y segunda dimensión del componente manejo de potreros.

El control manual de malezas está asociado con los MPG, es un método de baja carga ambiental, pero de elevada utilización de mano de obra. Es importante destacar que, la combinación de diferentes métodos de desmalezado (método mixto) estuvo relacionado principalmente con los MG y GG, lo cual podría indicar que estos productores se preocupan por la presencia de arvenses en las praderas. Similarmente, en sistemas de cría en Cundinamarca, Colombia, un alto número de productores combinaron diferentes métodos de desmalezado en sus fincas, entre los que se destacan el mecánico, manual y químico ${ }^{(23)}$.

Las variables numéricas, área de pasturas mejoradas, área fertilizada, tasa de fertilización y número de animales se relacionaron positivamente con la primera dimensión (Figura 3 (b)). La variable fertilización química estuvo vinculada a las fincas con más animales, sin embargo, menos del $28 \%$ de los ganaderos en todas las categorías implementaron esta práctica. Lo anterior se asemeja a lo reportado para sistemas de cría en Colombia, donde solo $14 \%$ de las explotaciones caracterizadas fertilizaron las pasturas ${ }^{(23)}$.

En la mayoría de las fincas, la fertilización química se hace al momento del establecimiento de la pastura y no realizan fertilización de mantenimiento. Las tasas de aplicación oscilaron entre $40 \mathrm{~kg}$ $\mathrm{N} \mathrm{ha}^{-1}$ año $^{-1}$ y $104 \mathrm{~kg} \mathrm{~N} \mathrm{ha}^{-1}$ año $^{-1}$, y las tasas más bajas correspondieron a los MPG y PG. Se han recomendado tasas entre 100 y $200 \mathrm{~kg} \mathrm{~N} \mathrm{ha}^{-1}$ año $^{-1}$ para praderas permanentes ${ }^{(26)}$, por lo tanto es posible que las dosis utilizadas no permitan que las pasturas alcancen sus rendimientos óptimos. Sin embargo, la dosis a utilizar depende del nivel de fertilidad, de las características físicas del suelo, variables ambientales, y tipo de cultivo establecido, entre otras.

\section{Información productiva y reproductiva}

Con respecto a las variables categóricas (Figura 4 (a)), hubo una clara tendencia de aglomeración de las variables relacionadas con el desarrollo de prácticas productivas y reproductivas hacia el lado derecho de la dimensión 1: pesaje al nacimiento y destete, monta controlada, inseminación artificial, transferencia de embriones, palpación a vacas, chequeo reproductivo a toros, pesaje de novillas de vientre para el primer servicio y separación del lote horro, además de la existencia de potrero de paridero, equipo de inseminación artificial e inseminador. Por el contrario, las variables 
relacionadas con el no desarrollo de las anteriores prácticas o actividades y la no existencia de dichas instalaciones o equipos se situaron hacia el lado izquierdo de dicha dimensión.

Figura 4: Proyección espacial (a) de las categorías de variables categóricas (a) y numéricas (b)
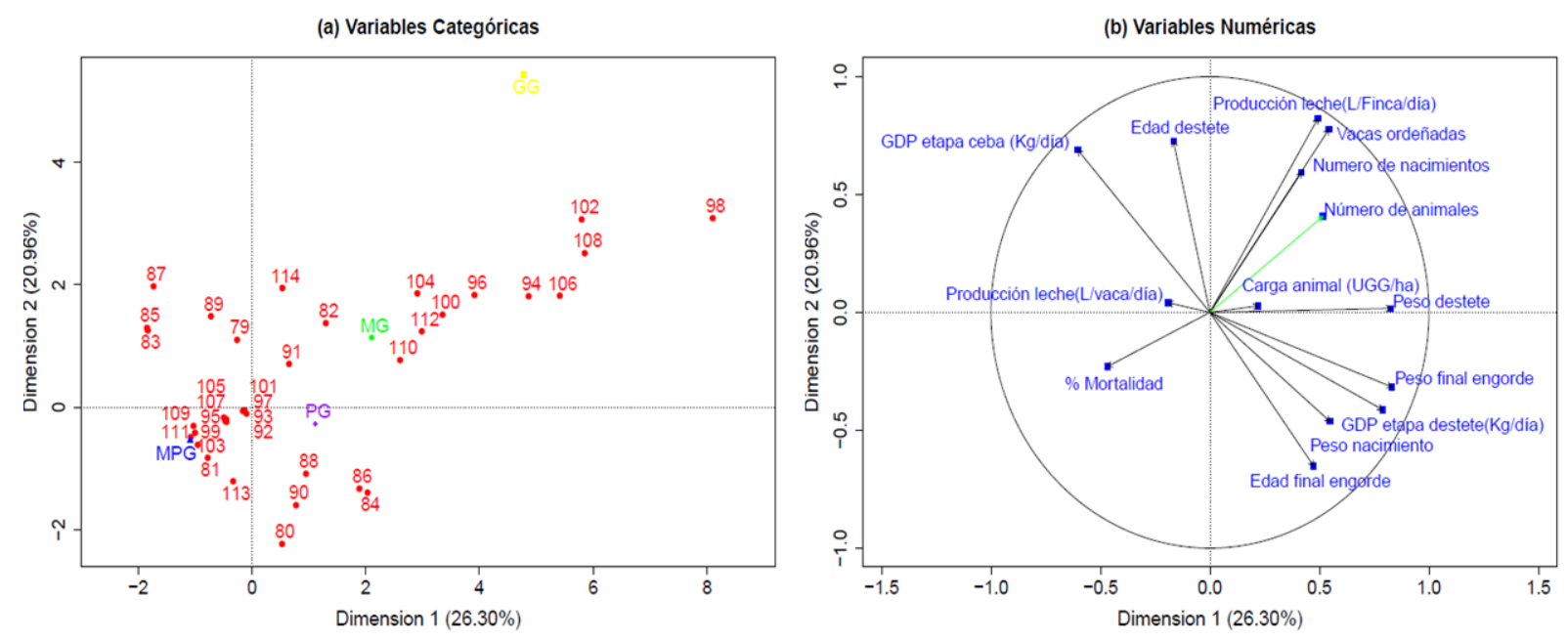

Proyección espacial (a) de las categorías de variables categóricas (GG: grandes ganaderos, MG: medianos ganaderos,

PG: pequeños ganaderos, MPG: muy pequeños ganaderos, 79: no pesa animales con cinta métrica, 80: si pesa animales con cinta métrica, 81: no pesa animales con báscula, 82: si pesa animales con báscula, 83: no pesa al nacimiento, 84: si pesa al nacimiento, 85: no pesa al destete, 86: si pesa al destete, 87: no cría al ternero macho, 88 : si cría al ternero macho, 89: no ceba animales, 90: si ceba animales, 91: no practica la monta natural, 92: si practica

la monta natural, 93: no practica la monta controlada, 94: si practica la monta controlada, 95: no practica la inseminación artificial, 96: si practica la inseminación artificial, 97: no realiza transferencia de embriones, 98: si realiza transferencia de embriones, 99: no realiza palpación a vacas, 100: si realiza palpación a vacas, 101: no realiza chequeo reproductivo a toros, 102: si realiza chequeo reproductivo a toros, 103: no pesa novillas de vientre para primer servicio, 104: si pesa novillas de vientre para primer servicio, 105: no tiene inseminador, 106: si tiene inseminador, 107: no tiene equipo de inseminación, 108: si tiene equipo de inseminación, 109: no separa el lote horro, 110: si separa el lote horro, 111: no tiene potrero de paridero, 112: si tiene potrero de paridero, 113: no determina el intervalo entre partos, 114: si determina el intervalo entre partos) y (b) numéricas (Carga animal

(UGG/ha): carga animal, Vacas ordeñadas: número de vacas en ordeño, Producción leche(L Finca-1 día-1), Producción leche(L Vaca-1 día-1), Peso nacimiento (kg): peso al nacimiento, Peso destete (kg): peso al destete, Edad destete: edad al destete, Edad final engorde: edad final de engorde, Peso final engorde: peso final de engorde, GDP etapa destete(Kg día-1): ganancia diaria de peso etapa de destete, GDP etapa ceba (Kg día-1): ganancia diaria de peso etapa de ceba, Número de nacimientos, \% Mortalidad: \% de mortalidad, Número de animales: número de bovinos) en la primera y segunda dimensión del componente información productiva y reproductiva de la ganadería.

En la dimensión 2, las variables relacionadas con el desarrollo de prácticas como pesaje de animales mediante cinta métrica, crianza del ternero macho y ceba de animales se aglomeraron en la parte inferior. El no desarrollo de las anteriores actividades se localizaron en la parte superior, además de la determinación del intervalo entre partos y pesaje de animales con báscula. Por tanto, los MG y GG desarrollaron mejores prácticas productivas y reproductivas que los MPG y PG. 
Las mejores prácticas reproductivas realizadas por MG y GG podrían traducirse en mayor productividad. También se ha mencionado que actividades como determinación del peso de las novillas de vientre para el primer servicio, chequeos reproductivos, uso de la inseminación artificial, disponibilidad de potreros para pariciones, separación del lote horro y determinación del intervalo entre partos no son habitualmente realizadas en fincas de pequeños ganaderos ${ }^{(23)}$. Las anteriores prácticas reproductivas en mayor medida se realizan en los sistemas ganaderos más especializados, con mayor capacidad económica, lo cual se traduce en altos índices de productividad $^{(7)}$.

Determinar el peso de los bovinos es importante para evaluar el crecimiento, planificar la alimentación y aprovechar los recursos alimenticios disponibles, manejar adecuadamente los registros de orden técnico y económicos, y desarrollar labores de observación, medicación, mejoramiento genético y manejo reproductivo ${ }^{(27)}$. El porcentaje de fincas que pesan los animales es más alto en MG y GG, lo que podría estar relacionado con la mayor disponibilidad de básculas. La barimetría posibilita estimar el peso vivo aproximado de un animal mediante medidas corporales y la aplicación de ciertas fórmulas ${ }^{(27)}$, por tanto, podría ser útil difundir y fomentar su uso en explotaciones de MPG y PG, donde la disponibilidad de básculas es baja. De esta manera, los ganaderos podrían tener mayor control de los índices productivos y aumentar la productividad de sus fincas.

En relación con edad al destete, número de vacas ordeñadas, número de nacimientos y producción total de leche $\left(\mathrm{L} \mathrm{finca}^{-1}\right.$ día $\left.^{-1}\right)$ se relacionaron positivamente entre sí y con la dimensión 2 (Figura 4 (b)). Una medida que podría mejorar el comportamiento reproductivo del hato es el destete temprano, el cual reduce los requerimientos energéticos de la vaca, lo que se traduce en el aumento de peso, mejora en la condición corporal e incremento de los porcentajes de preñez y mejor comportamiento reproductivo ${ }^{(28)}$. Sin embargo, aplicar esta medida requiere realizar un adecuado manejo nutricional a los terneros destetos, asegurándoles una oferta adecuada en cantidad y calidad de energía y proteína, lo que podría incurrir en gastos adicionales para los productores ${ }^{(29)}$.

El número de animales se relacionó negativamente con el porcentaje de mortalidad total (Figura 4 (b)). Lo contrario fue reportado por Holmann et $\mathrm{al}^{(30)}$ para sistemas ganaderos en Costa Rica, al observar que los índices de mortalidad tienden a ser menores en las fincas pequeñas (menos de 30 animales). Es importante indicar que en fincas pequeñas la muerte de un animal es proporcionalmente mayor que la muerte de un animal en fincas más grandes. Un menor índice de mortalidad podría traducirse en mayor rentabilidad y competitividad para la explotación ganadera e influenciar positivamente la obtención de ingresos económicos por los ganaderos.

La ganancia diaria de peso (GDP) predestete, y pesos al nacimiento y destete fueron más altos en los MG y GG. Madrid-Bury et $a l^{(31)}$ reportaron que crías con mayor peso al nacimiento presentaron 
un crecimiento más rápido y menor mortalidad. Estos mismos autores también indicaron una correlación positiva entre los pesos al nacimiento y al destete en bovinos de carne. Sin embargo, algunos estudios han indicado que crías con mayor peso al nacimiento no necesariamente serán las que alcancen mayor peso al destete ${ }^{(32,33)}$. Una mayor GDP predestete conlleva a la obtención de un mayor peso al destete, lo cual podría incidir en una mayor rentabilidad económica para la empresa ganadera, al vender animales más pesados para la ceba ${ }^{(32)}$.

\section{Información ambiental}

En este componente no existió separación del centroide (Figura 5), sugiriendo que no existieron patrones en el desarrollo e implementación de prácticas ambientales diferenciadas por categoría de productor. Con el fin de aumentar la implementación de buenas prácticas ambientales en las fincas, es importante involucrar estrategias que además de generar beneficios productivos y económicos a los productores, conlleven a beneficios ambientales como la mitigación y adaptación al cambio climático. Por ejemplo, la conservación de árboles y arbustos en potreros y los sistemas silvopastoriles son estrategias de producción que se han adoptado en sistemas ganaderos del trópico latinoamericano y que contribuyen a la reducción de las temperaturas extremas, conservación de la flora y fauna silvestre, regulación y calidad hídrica en cuencas hidrográficas, captura de carbono atmosférico, mitigación del cambio climático, además de mejorar la producción de leche y carne y la rentabilidad ganadera ${ }^{(34)}$.

Figura 5: Proyección espacial de las categorías de variables categóricas (a) y numéricas (b)

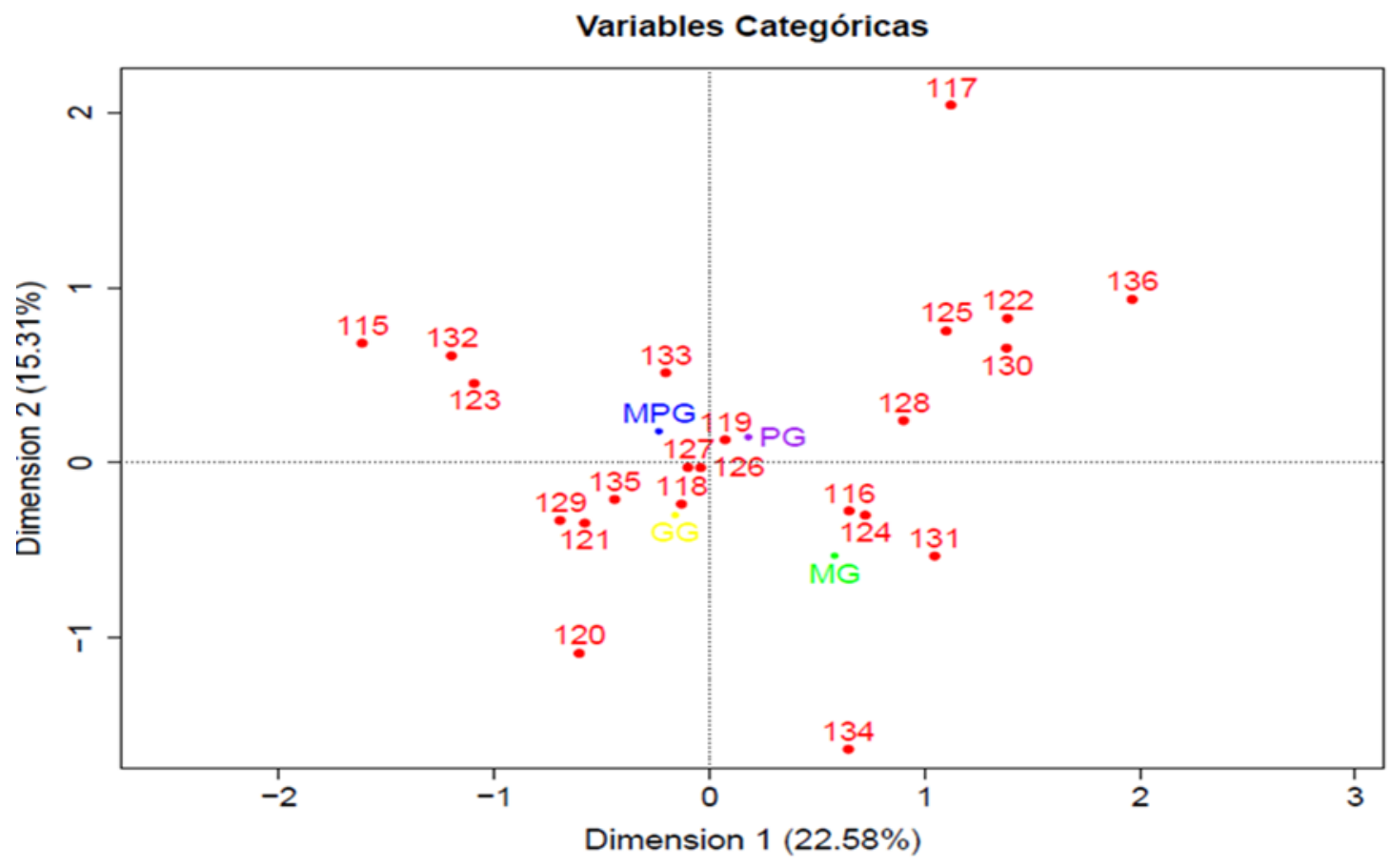


Proyección espacial de las categorías de variables categóricas (GG: grandes ganaderos, MG: medianos ganaderos, PG: pequeños ganaderos, MPG: muy pequeños ganaderos, 115: no tiene bosque, 116: si tiene bosque, 117: no usa agua superficial, 118: si usa agua superficial, 119: no usa agua subterránea, 120: si usa agua subterránea, 121: no usa agua de acueducto, 122: si usa agua de acueducto, 123: no tiene nacimientos de agua, 124: si tiene nacimientos de agua, 125: no tiene disponibilidad de agua en verano para uso pecuario, 126: si tiene disponibilidad de agua en verano para uso pecuario, 127: no tiene sistema de riego, 128: si tiene sistema de riego, 129: no tiene sistema de tratamiento de aguas residuales, 130: si tiene sistema de tratamiento de aguas residuales, 131: no incinera residuos sólidos, 132: si incinera residuos sólidos, 133: no entierra los residuos sólidos, 134: si entierra los residuos sólidos, 135: no entrega los residuos a terceros, 136: si entrega los residuos a terceros) en la primera y segunda dimensión del componente información ambiental.

Las aguas residuales generadas en los sistemas ganaderos provienen usualmente de la vivienda de la finca y el lavado de establos. Debido a la baja implementación de sistemas de tratamiento de aguas residuales en las fincas ( $<40 \%)$, los vertimientos, de generarse, se hacen directamente a las fuentes hídricas y suelo. Los principales tipos de tratamiento implementados en las fincas son los pozos sépticos y biodigestores, que corresponden a procesos primarios y secundarios de baja remoción de nutrientes. Por lo tanto, las descargas directas y los efluentes de los sistemas de depuración podrían generar problemas de eutrofización en los cuerpos de agua debido a la presencia de nitrógeno $(\mathrm{N})$ y fósforo $(\mathrm{P})$ procedentes de las excretas del ganado. Resulta entonces importante implementar sistemas de tratamiento terciarios, que permitan aumentar la remoción de nutrientes en el vertimiento y disminuir su potencial de eutrofización.

Los residuos sólidos no biodegradables se han catalogado como de los principales impactos ambientales de la cadena bovina en Colombia, sin embargo, la falta de estudios cuantitativos no permite estimar de manera precisa su magnitud ${ }^{(35)}$. La incineración y el enterramiento son las principales formas de manejo de residuos sólidos y se desarrollan en más del $70 \%$ de las fincas. La incineración genera emisiones de GEI que incrementan el potencial de calentamiento global, mientras que el enterramiento sin ningún control sanitario podría contribuir a la contaminación de acuíferos. Por tanto, realizar la caracterización y aforo de los residuos sólidos en las fincas, es una medida importante que permite evaluar de forma cuantitativa la magnitud de los impactos negativos que se podrían generar y establecer estrategias de manejo para minimizarlos.

\section{Conclusiones e implicaciones}

En los componentes información general de la finca, composición y manejo del hato, manejo de potreros, e información productiva y reproductiva, las variables incluidas conllevaron a una separación espacial del centroide de cada categoría de ganadero. Como comportamiento general, los medianos y grandes ganaderos estuvieron asociados con variables que indican la existencia de mejor infraestructura, maquinaria y equipo, mejores prácticas de manejo de pasturas y mejores parámetros reproductivos y productivos. A su vez, estas categorías podrían estar asociadas con mayor capacidad económica. El componente ambiental fue el único que no mostró separación del 
centroide de los grupos de fincas, lo que sugiere que no existen marcadas diferencias en el desarrollo e implementación de prácticas ambientales de acuerdo con el tamaño de la unidad de producción. Es necesario definir los aspectos ambientales más relevantes de los sistemas ganaderos para incluirlos en futuros estudios de caracterización, y de este modo aumentar el acervo de conocimiento de los impactos ambientales asociados a la ganadería. Las principales características identificadas para cada categoría de ganadero pueden servir de base para la orientación y establecimiento de políticas y programas de desarrollo tecnológico. De acuerdo con la distribución porcentual de las fincas y las características de los muy pequeños y pequeños ganaderos, estas categorías podrían ser consideradas, en mayor medida, para la implementación de algunas de las acciones de mitigación establecidas en la NDC de Colombia como: pastoreo racional, rehabilitación de pasturas y sistemas silvopastoriles intensivos.

\section{Agradecimientos}

Este estudio hace parte del proyecto LivestockPlus financiado por el Programa de Investigación del CGIAR (CPR por sus siglas en inglés) en Cambio Climático, Agricultura y Seguridad Alimentaria (CCAFS por sus siglas en inglés). Adicionalmente, este trabajo fue desarrollado como parte del CPR en Ganadería. Agradecemos a todos los donantes que globalmente apoyan el trabajo de todos los CPR mediante sus contribuciones al sistema CGIAR. Estamos igualmente agradecidos con el Proyecto Ganadería Colombiana Sostenible implementado por la Federación Colombiana de Ganaderos (FEDEGAN-FNG), la Fundación para la Investigación en Sistemas Sostenibles de Producción Agropecuaria (CIPAV), Fondo Acción, y The Nature Conservancy (TNC). Este trabajo fue apoyado por el Global Environmental Fund (GEF), donantes del Fondo CGIAR y mediante acuerdos de financiación bilaterales (para más detalles por favor visite https://ccafs.cgiar.org/donors), y Colciencias (convocatoria 727 de 2015).

\section{Literatura citada:}

1. FAO. FAOSTAT. Agricultural Production. Rome; 2013. http://www.fao.org/faostat/en/\#home

2. ICA. Censo Pecuario Nacional 2018. Bogotá DC. 2018. https://www.ica.gov.co/areas/pecuaria/servicios/epidemiologia-veterinaria/censos2016/censo-2018

3. DANE. Encuesta Nacional Agropecuaria 2016. Bogotá DC. 2017. https://www.dane.gov.co/index.php/estadisticas-por-tema/agropecuario/encuesta-nacionalagropecuaria-ena

4. Fedegán. Estadísticas. 2019. http://www.fedegan.org.co/estadisticas/produccion-0 
5. Páez L, Tiburcio L, Sayago W, Pacheco R. Caracterización estructural y funcional de fincas ganaderas de doble propósito en el municipio Páez del estado Apure, Venezuela. Zootec Trop 2003;21(3):301-320.

6. MADS. Ministerio de Ambiente y Desarrollo Sostenible. Documento técnico soporte de la INDC de Colombia. Bogotá, DC. 2015.

7. Holmann F, Rivas L, Carulla J, Giraldo L, Guzmán S, Martínez M, et al. Evolución de los Sistemas de Producción de Leche en el Trópico Latinoamericano y su interrelación con los Mercados: Un Análisis del Caso Colombiano. Cali. IICA; 2003.

8. Fedegán. Plan estratégico de la ganadería colombiana 2019 - Por una ganadería moderna y solidaria. Vol. 1, PEGA 2019. Bogotá, DC. 2006.

9. R Core Team: A Language and Environment for Statistical Computing. Vienna, Austria: R Foundation for Statistical Computing; 2016.

10. Pagès J. Analyse factorielle de donnees mixtes: principe et exemple d'application. Montpellier SupAgro. 2004.

11. Josse J, Husson F. missMDA: A package for handling missing values in multivariate data analysis. J Stat Softw 2016;70(1):1-31.

12. Ríos-Núñez S, Benítez-Jiménez D. Análisis del funcionamiento económico productivo de los sistemas de producción cárnica bovina en la Amazonía Ecuatoriana. Arch Zootec 2015;(64):409-416.

13. Chalate-Molina H, Gallardo-López F, Pérez-Hernández P, Lang-Ovalle FP, Ortega-Jiménez E, Vilaboa-Arroniz J. Características del sistema de producción bovinos de doble propósito en el estado de Morelos, México. Zootec Trop 2010;28(3):329-339.

14. Urquía-Fernández N. La seguridad alimentaria en México. Salud Publica Mex 2014;(56):9298.

15. Sadeghian S, Rivera JM, Gómez M. Impacto de sistemas de ganadería sobre las características físicas, químicas y biológicas de suelos en los andes de Colombia. FAO-CIPAV. Conferencia electrónica de la FAO sobre "Agroforestería para la producción animal en Latinoamérica". Cali; 2000:77-95.

16. Vargas J, Benítez D, Torres V, Velázquez F, Erazo O. Tipificación de las fincas ganaderas en el piedemonte de las provincias Los Ríos y Cotopaxi de la República del Ecuador. Rev Cuba Cienc Agrícola 2011;45(4):381. 
17. Naranjo JF, Cuartas CA, Murgueitio E, Chará J, Barahona R. Balance de gases de efecto invernadero en sistemas silvopastoriles intensivos con Leucaena leucocephala en Colombia. LRRD 2012;24(8).

18. Villa-Herrera A, Nava-Tablada ME, López-Ortiz S, Vargas-Lopez S, Ortega-Jiménez E, López FG. Utilización del Guácimo (Guazuma ulmifolia Lam.) como fuente de forraje en la ganadería bovina extensiva en el trópico mexicano. Trop Subtrop Agroecosystems 2009;10(2):253-261.

19. Mahecha-Ledesma L, Gallego L, Peláez F. Situación actual de la ganadería de carne en Colombia y alternativas para impulsar su competitividad y sostenibilidad. RCCP 2002;15(2):213-225.

20. Gómez-Castro H, Tewolde A, Nahed-Toral J. Análisis de los sistemas ganaderos de doble propósito en el centro de Chiapas, México. Arch Latinoam Prod Anim 2002;10(3):175-183.

21. Sierra-Roncancio SS, Cano-Muñoz JG, Rojas-Sánchez F. Estrategias de adaptación al cambio climático en dos localidades del municipio de Junín, Cundinamarca, Colombia. Rev Investig Agrar Ambient 2015;6(1):227-237.

22. Rosero-Noguera R, Posada-Ochoa SL. Cálculo de sales minerales para vacunos en pastoreo. 1st ed. Fondo Editorial Biogénesis; 2016:1-29.

23. Villate-Calderón JA, Martínez-Roldán CM. Tipificación y diagnóstico de sistemas de producción bovina de ceba, cria y doble propósito, para pequeños y medianos productores de la provincia de Medina, Cundinamarca [tesina pregrado]. Bogotá, DC: Universidad de la Salle; 2011.

24. Ruiz TE, Castillo E, Alonso J, Febles G. Factores de manejo para estabilizar la producción de biomasa con leguminosas en el trópico. Avances en Investigación Agropecuaria 2006; 10(1):3-20.

25. Arango J, Gutiérrez J, Mazabel J, Pardo P, Enciso K, Burkart S, et al. Estrategias tecnológicas para mejorar la productividad y competitividad de la actividad ganadera: Herramientas para enfrentar el cambio climático. Cali, Colombia: CIAT; 2016: (414):1-58.

26. Bernier R, Undurraga P. Fertilización de praderas permanentes para la producción de leche. Manual de producción de leche para pequeños y medianos productores. INIA; 2009:(148).

27. Mahecha-Ledesma L, Angulo J, Manrique LP. Predicción del peso vivo a través del perímetro torácico en la raza bovina Lucerna. RCCP 2002;15(1):88-91.

28. Hudson MD, Banta JP, Buchanan DS, Lalman DL. Effect of weaning date (normal vs late) on 
performance of young and mature beef cows and their progeny in a fall calving system in the Southern Great Plains. J Anim Sci 2010;88(4):1577-1587.

29. Schor A, Guibelalde G, Grigera-Naón JJ. Efecto de la fecha de destete sobre la performance de vientres y terneros. Rev Argentina Prod Anim 2015;(25):179-188.

30. Holmann F, Rivas L, Pérez E, Castro C, Schuetz P, Rodríguez J. La cadena de carne bovina en Costa Rica: identificación de temas críticos para impulsar su modernización, eficiencia y competitividad. Cali-Colombia: CIAT;2007:(206):1-70.

31. Madrid-Bury N, González-Stagnaro C, Goicochea-Llaque J, González-Villalobos D, Rodríguez-Urbina MA. Peso al nacimiento en hembras bovinas doble propósito. Rev Fac Agron 2007;24(4):690-708.

32. Arboleda-Zapata EM, Vergara-Garay OD, Restrepo LF. Características de crecimiento en bovinos mestizos en la costa norte colombiana. LRRD 2007;19(5).

33. Montes D, Vergara O, Prieto E, Rodríguez A. Estimación de los parámetros genéticos para el peso al nacer y al destete en ganado bovino de la raza Brahman. Rev MVZ Córdoba 2008;13(1):1184-1191.

34. Murgueitio E, Xóchitl Flores M, Calle Z, Chará J, Barahona R, Molina CH, et al. Sistemas agroforestales. Funciones productivas, socioeconómicas y ambientales. Productividad en sistemas silvopastoriles intensivos en América Latina. Cali - Colombia; 2015:(402):57-101.

35. Murgueitio E. Impacto ambiental de la ganadería de leche en Colombia y alternativas de solución. LRRD 2003;15(10). 